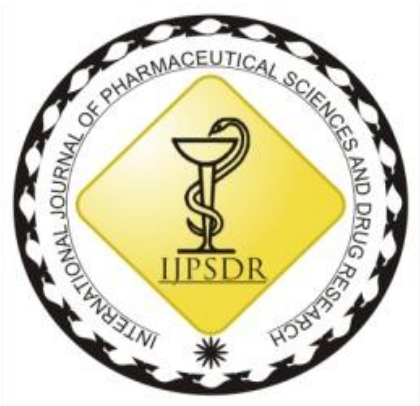

ISSN: 0975-248X

RESEARCH ARTICLE CODEN (USA): IJPSPP

$(\mathrm{cc})$ EY-NC-SA

\title{
Evaluation of Anticonvulsant Activity of Ethanolic Extract of Leaves of Cajanus cajan (L) Millsp. In Rodents
}

\author{
Ankita Prakash Kore*, Nilofar Shahnwaj Naikwade, Padma Laxmikant Ladda, \\ Tabbasum Shabbirahmad Shikalgar, Shirish Sidgonda Patil
}

Department of Pharmacology, Appasaheb Birnale College of Pharmacy (ABCP), Sangli-416416, Maharashtra, India

Copyright (C) 2019 Ankita Prakash Kore et al. This is an open access article distributed under the terms of the Creative Commons AttributionNonCommercial-ShareAlike 4.0 International License which allows others to remix, tweak, and build upon the work non-commercially, as long as the author is credited and the new creations are licensed under the identical terms.

\begin{abstract}
Cajanus cajan (L) Millsp. is the perennial plant belongs to family Fabaceae, commonly called as Pigeon pea plant. The presence of phytoconstituents like flavonoids, the flavanone (substituted) from Cajanus cajan (L) Millsp. have in vitro neuroactive property. This flavanone named as pinostrobin helps to inhibit voltage - gated sodium channels. Because of its bioactive phytoconstituents it may act as antiepileptic drug. To avoid problems like ADR herbal plant might be alternative to treat epilepsy. The current study was therefore carried out to evaluate antiepileptic activity of Ethanolic extract of leaves of Cajanus cajan in rodents. The effect of ELECC in MES-induced convulsions in rat and PTZ-induced convulsion in mice was evaluated using doses $100 \mathrm{mg} / \mathrm{kg}$ and $200 \mathrm{mg} / \mathrm{kg}$ for 7 days. Phenytoin (25 $\mathrm{mg} / \mathrm{kg}$ ), Diazepam ( $4 \mathrm{mg} / \mathrm{kg}$ ) was used as standard drug for respective model. Depending on the model, outcome measures were abolishment of Hind Limb Tonic Extensor phase in MES-induced convulsion in rat and onset of latency, recovery or death in PTZ-induced convulsion in mice as well as biochemical estimation of amino acid neurotransmitter (GABA, Glutamate) were evaluated. The ELECC at doses 100 and $200 \mathrm{mg} / \mathrm{kg}$ significantly delayed the HLTE phase in MES-induced convulsions in rat whereas, significantly increased onset of latency in PTZ-induced convulsion in mice. It also showed significant $(p>0.0001)$ effect on the level of GABA and Glutamate in dose dependent manner in both models. The phytochemical study of $C$. cajan showed the presence of Glycosides, Flavonoids, Flavonones, Steroids, Tannins, Fixed oil, Fatty acids and Proteins. As the flavonoids present in C. cajan may contribute to the anticonvulsant activity of the plant. Therefore, the presence of such compounds in the extract may be responsible for the anticonvulsant effect. Therefore, present study validates its anticonvulsant activity. Further, research is required to elucidate its specific mechanism of action and isolation of responsible active principles.
\end{abstract}

Keywords: Epilepsy, Antiepileptic drugs, Ethanolic extract, Cajanus cajan (L) Millsp.

DOI: 10.25004/IJPSDR.2019.110608

Int. J. Pharm. Sci. Drug Res. 2019; 11(6): 330-336

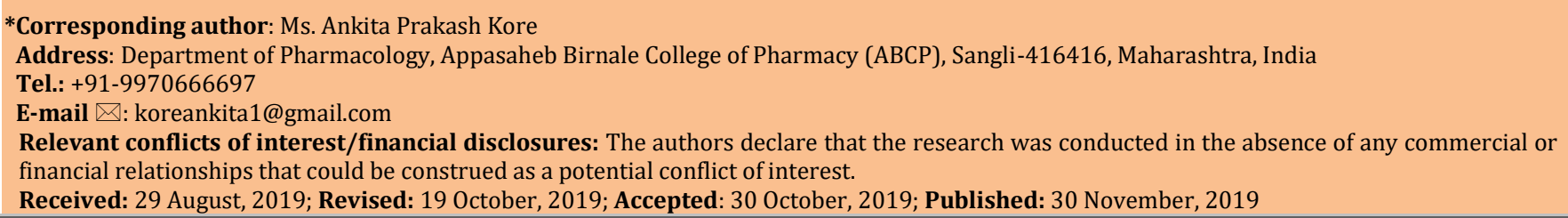

\section{INTRODUCTION}

Epilepsy is the common neurological abnormality. It is a hyper-excitation of neurons in the brain which leads to altered behaviour with/without violent motor activity. [1] Literally "Epilepsy" is a Greek word which is derived from 'epilambanein' meaning 'to be 
seized'/'to be overwhelmed' by shock. [2] It is a disorder characterized by the periodic as well as random occurrences of seizures which are followed by spontaneous resolution. [1] Chemical reactions are used by brain cells i.e. neurons to produce electrical discharges and each brain cell either excites or inhibits other neurons with its discharges. The balance between the excitation and inhibition in a region of brain is necessary if moves too far in the direction of excitation, and it results into seizure formation. [3]

Convulsion is the second most common neurologic disorder after stroke. ${ }^{4]}$ Approximately that there are 55 lakhs people suffering from epilepsy in India, 20 lakh in USA and 3 lakhs in UK. The epilepsies affect more than 50 million people worldwide. Each year about 1, 25,000 new epilepsy cases arises out of these $30 \%$ are in people who are smaller than 19 years age at time of diagnosis. [5] It is common in adults over 60 as in children under $10,25 \%$ of all cases develop before the age of 5years. Unlike genetic type of epilepsy, the specifically acquired epilepsy accounts for about $60 \%$ of all instances and is generally preceded by injury for example an episode of extended seizure or status epilepticus, febrile seizures in children, hypoxia or trauma. [6]

Most of the epileptic patients need polytherapy of conventional antiepileptics and still not $100 \%$ cure. The WHO estimated that approximately $80 \%$ patients with epilepsy live in developing country like India and most of them do not get adequate treatment. [7] In antiepileptic drug therapy one third of patients remain unresponsive to the treatment. Cognitive impairment is major issue associated with long term use of antiepileptics. In addition to this oxidative stress is recently included in the pathogenesis and progression of seizures. To avoid such problems herbal plant might be alternative to treat epilepsy. [4]

Phytomedicines may play a main part in the growth of innovative antiepileptic drugs for patients who are pharmacoresistant. [8] There are many herbal plants like Argyreia specicosa, Allium cepha, Lycopersicon esculentum, Azima tetracantha possesses remarkable antiepileptic activity. Hence, use of plant derived products in antiepileptic treatment, may reduce or nullify adverse side effects.

Cajanus cajan (L) Millsp. is the perennial plant from family-Fabaceae, commonly called as a Pigeon pea plant. The reported pharmacological activity of Cajanus cajan (L) Millsp. are Antimicrobial, Antibacterial, Hypocholestrolemic, and Antidibetic etc. It also possesses Neuroactive property as well as Antioxidant, Anticancer, Hepatoprotective and Anthelmintic activity. Cajanus cajan (L) Millsp. leaves have different chemical constituents like flavonoids and stillbenes. It also contains saponins, noticeable amount of tannins and sensible quantities of reducing sugar, resins and terpenoids. [9] The presence of various phytoconstituents such as flavonoids, the Cajanus cajan
(L) Millsp's substituted flavanone possesses a in vitro neuroactive property. This substituted flavanone, pinostrobin inhibits voltage-gated sodium channels. Because of its bioactive phytoconstituents it may act as antiepileptic drug. [9-10]

In light to above it is appropriate to screen antiepileptic activity of herbal plant. To avoid such problems like ADR herbal plant might be alternative to treat epilepsy.

\section{MATERIALS AND METHODS}

\section{Preparation of extract}

Leaves of plant Cajanus cajan (L) Millsp. were collected in month of September and October 2018 from Kumbhoj region (Dist - Kolhapur) Maharashtra (India) and Authenticated by Prof. M. D. Wadmare, Department of Botany from Smt. Kasturbai Walchand College Sangli.

The leaves were plucked out from the stems and shed dried for a week at room temperature. Then leaves were ground with mixer grinder to get coarse powder and it stored in airtight container. Weighed quantity of powder was extracted using ethanol as a solvent in Soxhelet apparatus at $\left(45-60^{\circ} \mathrm{C}\right)$ boiling point of solvent and extract was concentrated at room temperature using desicator. The final extract was weighed and the percentage of extract was calculated using formula:

Percentage extract obtained $=\mathrm{Wt}$. of extract $(\mathrm{g}) / \mathrm{Wt}$. of sample $(\mathrm{g}) \times 100$

\section{Phytochemical Investigation}

Phytochemical tests were carried out to find the presence of various phytoconstituents viz. Carbohydrates, Alkaloids, Proteins, Glycosides, Flavonoids, Steroids and Tannins in the leaves. [11]

\section{Animals}

Wistar Rat of any sex weighing 150-200 g and Swiss albino mice of either sex weighing 20-30 g were procured from animal house of Appasaheb Birnale College of Pharmacy, Sangli and were used for the study. Form B protocol were prepared and submitted to Institutional Animal Ethics committee (IAEC). Animals were housed in finely- ventilated room at $23 \pm$ $2{ }^{\circ} \mathrm{C}$, with humidity of $65-70 \%$, and they were feed with a standard pellet diet with mineral water. Procedures involving laboratory animals were performed in accordance with the guidelines of the Committee for the Purpose of Control and Supervision of Experiments on Animals (CPCSEA). Approval for animal use was obtained from IAEC prior to experimental study. The experimental protocol (IAEC/ABCP/01/2018-19) was approved by the IAEC.

Toxicity study

According to literature survey the $\mathrm{LD}_{50}$ of ethanolic extract of Cajanus cajan (L) Millsp. was found to be 1000 $\mathrm{mg} / \mathrm{kg}$ and again cross checked and it was found to be safe. [10]

\section{Dose selection}

According to OECD guidelines as the $\mathrm{LD}_{50}$ of ethanolic extract of Cajanus cajan (L) Millsp. was found to be 1000 $\mathrm{mg} / \mathrm{kg}$ then two doses are selected for further 
evaluation as $1 / 10^{\text {th }}$ and $1 / 5^{\text {th }}$ i.e. $100 \mathrm{mg} / \mathrm{kg}$ and 200 $\mathrm{mg} / \mathrm{kg}$ respectively.

Experimental Design [12-13]

Maximal Electroshock Induced Convulsions in Rats

Wistar rats of 6-8 weeks of either sex weighing to 150 $200 \mathrm{~g}$ were randomly selected and marked to permit individual identification, and further grouped into four groups each group comprising 6 animals.

Control: Distilled water $(5 \mathrm{ml} / \mathrm{kg}$, p.o. $)$

Standard: Phenytoin $(25 \mathrm{mg} / \mathrm{kg}$, i.p. $)$

Test I: Ethanolic leaves extract of Cajanus cajan (L) Millsp. (100 mg/kg, p.o.)

Test II: Ethanolic leaves extract of Cajanus cajan (L) Millsp. (200 mg/kg, p.o.)

The test drug was administered continuously for the period of 7 days. On $7^{\text {th }}$ day convulsions were induced by MES. Phenytoin $(25 \mathrm{mg} / \mathrm{kg})$ as standard was injected by intraperitoneal route, $30 \mathrm{~min}$ before induction and control group were received distilled water by oral route $60 \mathrm{~min}$ prior to induction. Maximal electroshock seizures were elicited by a $150 \mathrm{~mA}$ current for $0.2 \mathrm{sec}$. And different stages of convulsion were observed i.e. (a) tonic extensor phase (b) tonic flexion (c) clonic convulsions (d) stupor as well as recovery /death. Then the decreased in time or elimination of tonic extensor phase of MES-convulsion was recorded. The number of animals survived within the period of observation was expressed as \% protection. Further animals were sacrificed by using $\mathrm{CO}_{2}$ euthanasia chamber and dissected and brain was isolated and used for estimation of amino acid neurotransmitters i.e. GABA and Glutamate.

Pentylenetetrazol (PTZ) Induced Convulsions in Mice Swiss albino mice of 4-6 weeks of either sex weighing to 20-30 g were randomly selected and marked to permit individual identification, and further grouped into four groups each group comprising 6 animals.

Control: Distilled water $(5 \mathrm{ml} / \mathrm{kg}$, p.o. $)+$ PTZ (80 $\mathrm{mg} / \mathrm{kg}$, i.p.)

Standard: Diazepam (4 mg/kg, i.p.) + PTZ $(80 \mathrm{mg} / \mathrm{kg}$, i.p.)

Test I: Ethanolic leaves extract of Cajanus cajan (L) Millsp. (100 mg/kg, p.o.) + PTZ (80 mg/kg, i.p.)

Test II: Ethanolic leaves extract of Cajanus cajan (L) Millsp. $(200 \mathrm{mg} / \mathrm{kg}$, p.o. $)+$ PTZ $(80 \mathrm{mg} / \mathrm{kg}$, i.p. $)$

The test drug was administered continuously for the period of 7 days. On $7^{\text {th }}$ day convulsions were induced by PTZ. All animal groups were injected with PTZ, along with after administering respective treatment prior to experiment.

The onset of action (indicate by Straub's tail, jerky movements of whole body and convulsions) and intensity of convulsions were noted for all groups. The number of animals survived within the period of observation was expressed as \% protection. Further animals were sacrificed by using $\mathrm{CO}_{2}$ euthanasia chamber and dissected and brain was isolated and used for estimation of amino acid neurotransmitters i.e. GABA and Glutamate.

\section{Biochemical Estimation}

Dissection and Homogenization of brain

The animals were sacrificed by using $\mathrm{CO}_{2}$ euthanasia chamber. The weighed quantity of animal brain was homogenized with $5 \mathrm{ml}$ of $\mathrm{HCl}$ - Butanol.

Tissue preparation [14]

On experimental day the brain was dissected and forbrain were separated. Weighed quantity of tissue was homoginated using instrument tissue homoginiser then homoginate was centrifuged for $10 \mathrm{~min}$. at 2000 rpm. In $1 \mathrm{ml}$ of supernatant added $2.5 \mathrm{ml}$ of n-Heptane with $0.31 \mathrm{ml}$ of $0.1 \mathrm{M} \mathrm{HCl}$ centrifuged at $2000 \mathrm{rpm}$ for 10 min (after vigorous shaking). Organic and aqueous phase were obtained, further $0.2 \mathrm{ml}$ of aq. phase was collected for estimation of the GABA and Glutamate.

Paper Chromatography [15]

The aqueous phase of homogenate directly applied on the Whatman filter paper. It was put as a solvent scheme on a chamber comprising n-butanol: acetic acid: water (12: 3: $5 \mathrm{v} / \mathrm{v})$. It was removed and dried when the solvent reached the peak of the document. Similarly, at second time carried out after which the papers were sprayed by Ninhydrin reagent and kept for $4-5$ minutes in an oven at $100^{\circ} \mathrm{C}$ for drying. Then the portions which carry Glutamate and GABA corresponding with the standard were cut and soaked using solvent mixture of $0.005 \% \mathrm{CuSO}_{4}$ in $75 \%$ ethanol. Their absorbance was interpreted against blank at 514/515 nm for Glutamate and $550 \mathrm{~nm}$ for GABA in JASCO UV-Visible double beam spectrophotometer.

\section{Calibration Curve [16}

2.5 to $60 \mu \mathrm{g} / \mathrm{ml}$ solutions of Standard GABA and Glutamate were used. Graphs were plotted with concentration in $\mu \mathrm{g} / \mathrm{ml}$ on ordinate and absorbances on abscissa, the regression analysis was done using Microsoft - Excel 2007 and $\mathrm{R}^{2}$ value, slope by the equation of $y=m x+c$ was obtained for the straightline graphically obtained.

Statistical Analysis

The analysis of data was articulated as Mean \pm SEM. The comparisons between the averages of series of values were performed by one - way ANOVA test followed by Dunnett's' $t^{\prime}$ test.

\section{RESULTS}

Average \% yield of Ethanolic leaves extract of Cajanus cajan (L) Millsp. (ELECC) was found to be $35.2 \% \mathrm{w} / \mathrm{w}$. Phytochemical screening of Ethanolic leaves extract of Cajanus cajan (L) Millsp. plant was carried out. It showed the presence of Glycosides, flavonoids, steroids, tannins, fixed oil, fatty acids and proteins. The Ethanolic leaves extract of Cajanus cajan (L) Millsp. (ELECC) revealed significant anticonvulsant activity in both the models.

MES-induced convulsion in rats

The Ethanolic leaves extract of Cajanus cajan (L) Millsp. (ELECC) in selected doses $100 \mathrm{mg} / \mathrm{kg}$ and $200 \mathrm{mg} / \mathrm{kg}$ prevented convulsions against MES (150 mA current for $0.2 \mathrm{sec}$.) induced convulsion in rats. 
Ankita Prakash Kore et al. / Evaluation of Anticonvulsant Activity of Ethanolic Extract of Leaves of Cajanus..........

Table 1: Effect of ELECC on MES-induced convulsions in rats

\begin{tabular}{|c|c|c|c|c|c|}
\hline \multirow{2}{*}{ S. No. } & \multirow{2}{*}{ Drug treatment } & \multicolumn{4}{|c|}{ Types of Convulsions (Sec.) } \\
\hline & & Tonic Flexion & Tonic Extensor & Tonic Clonus & Stupor \\
\hline 1. & Control - Distilled water (5 ml/kg) & $10.33 \pm 0.760$ & $17.67 \pm 1.33$ & $6.167 \pm 0.477$ & $43.33 \pm 1.382$ \\
\hline 2. & Standard - Phenytoin (25 mg/kg) & $4.183 \pm 0.403^{* * * *}$ & $0.000 \pm 0.000^{* * * *}$ & $4.667 \pm 0.881$ & $4.167 \pm 0.7038^{* *}$ \\
\hline 3. & Test-I - ELECC (100 mg/kg) & $7.500 \pm 0.562^{* *}$ & $5.833 \pm 0.3073^{* * * *}$ & $3.500 \pm 0.223^{* *}$ & $41.50 \pm 1.875$ \\
\hline 4. & Test-II - ELECC (200 mg/kg) & $6.333 \pm 0.4216^{* * *}$ & $4.667 \pm 0.469^{* * * *}$ & $3.33 \pm 0.210^{* *}$ & $33.83 \pm 1.400^{* *}$ \\
\hline
\end{tabular}

ELECC- Ethanolic Leaves Extract of Cajanus cajan (L) Millsp. Each value was expressed in a Mean \pm SEM. The obtained results were analysed by statistically using one - way - ANOVA followed by Dunnett' $\mathrm{s}^{\prime \prime} \mathrm{t}^{\prime}$ test $(\mathrm{n}=6)$. Significant $\mathrm{P}$ values are ${ }^{* *}$ regarded to be $P<0.05$ and $\mathrm{d}^{* * *} P<0.0001$.

Table 2: Protective effect of ELECC in MES-induced mortality

\begin{tabular}{cccc}
\hline S. No. & Drug Treatment & No. of animals survived & \% Protection \\
\hline 1. & Control - Distilled water $(5 \mathrm{ml} / \mathrm{kg})$ & $2 / 6$ & $33.33 \%$ \\
2. & Standard - Phenytoin $(25 \mathrm{mg} / \mathrm{kg})$ & $6 / 6$ & $100 \%$ \\
3. & Test-I - ELECC $(100 \mathrm{mg} / \mathrm{kg})$ & $4 / 6$ & $66.66 \%$ \\
4. & Test-II - ELECC $(200 \mathrm{mg} / \mathrm{kg})$ & $5 / 6$ & $83.33 \%$ \\
\hline
\end{tabular}

Table 3: Level of amino acid neurotransmitter (GABA, Glutamate) in MES-induced convulsions in rats

\begin{tabular}{|c|c|c|c|}
\hline S. No. & Drug Treatment & GABA $(\mu \mathrm{g} / \mathrm{ml})$ & Glutamate $(\mu \mathrm{g} / \mathrm{ml})$ \\
\hline 1. & Control - Distilled water (5 ml/kg) & $0.120 \pm 0.027$ & $2.675 \pm 0.049$ \\
\hline 2. & Standard - Phenytoin $(25 \mathrm{mg} / \mathrm{kg})$ & $1.216 \pm 0.003^{* * * *}$ & $2.12 \pm 0.106^{* * * *}$ \\
\hline 3. & Test-I - ELECC (100 mg/kg) & $0.744 \pm 0.154^{* *}$ & $2.352 \pm 0.049^{*}$ \\
\hline 4. & Test-II - ELECC (200 mg/kg) & $0.895 \pm 0.202^{* *}$ & $1.977 \pm 0.075^{* * * *}$ \\
\hline
\end{tabular}

Table 4: Effect of ELECC in PTZ induced convulsions in mice

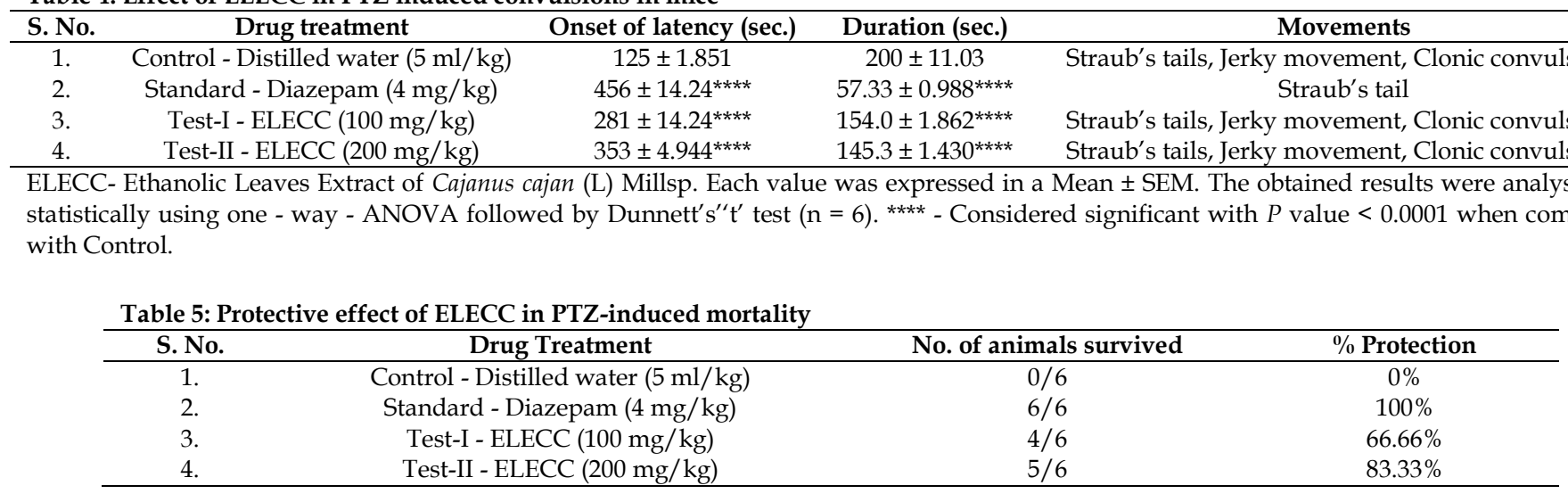

Table 6: Level of amino acid neurotransmitter (GABA, Glutamate) in PTZ-induced convulsions in mice

\begin{tabular}{cccc}
\hline S. No. & Drug Treatment & GABA $(\boldsymbol{\mu g} / \mathbf{m l})$ & Glutamate $(\boldsymbol{\mu g} / \mathbf{m l})$ \\
\hline 1. & Control - Distilled water $(5 \mathrm{ml} / \mathrm{kg})$ & $0.1818 \pm 0.005$ \\
2. & Standard - Diazepam $(4 \mathrm{mg} / \mathrm{kg})$ & $0.4528 \pm 0.008^{* * * *}$ & $3.320 \pm 0.030$ \\
3. & Test-I - ELECC $(100 \mathrm{mg} / \mathrm{kg})$ & $0.2274 \pm 0.004^{* * * *}$ & $3.663 \pm 0.112^{* * * * *}$ \\
4. & Test-II - ELECC $(200 \mathrm{mg} / \mathrm{kg})$ & $0.2830 \pm 0.002^{* * * *}$ & $3.435 \pm 0.061^{* * * *}$ \\
\hline
\end{tabular}

ELECC- Ethanolic Leaves Extract of Cajanus cajan (L) Millsp. Each value was expressed in a Mean \pm SEM. The obtained results were analysed by statistically using one - way - ANOVA followed by Dunnett' $\mathrm{s}^{\prime \prime} \mathrm{t}^{\prime}$ test $(\mathrm{n}=6) .{ }^{* * *}$ - Considered significant with $P$ value $<0.0001$ when compared with Control.

At both doses there was significant $(P<0.0001)$ decrease in the duration of Hind Limb Tonic Extensor (HLTE) phase in dose dependent manner where as complete abolishment of Hind Limb Tonic Extensor (HLTE) was seen in Phenytoin treated standard group (Table 1). Protective effect of ELECC against MES-induced mortality was found to be $66.66 \%$ and $83.33 \%$ protection for $100 \mathrm{mg} / \mathrm{kg}$ and $200 \mathrm{mg} / \mathrm{kg}$ of doses respectively (Table 2 ).

In respected model, the level of Amino Acid Neurotransmitter GABA (Gamma-amino butyric acid) was significantly $(P<0.0001)$ elevated whereas, level of Glutamate was significantly reduced $(P<0.0001)$ by ELECC treated group in dose dependent manner when compared with control which is comparable to respective standard groups (Table 3 ).

PTZ-induced convulsions in mice

The Ethanolic leaves extract of Cajanus cajan (L) Millsp. (ELECC) in selected doses $100 \mathrm{mg} / \mathrm{kg}$ and $200 \mathrm{mg} / \mathrm{kg}$ prevented convulsions against Pentylenetetrazol (PTZ, $80 \mathrm{mg} / \mathrm{kg}$, i.p.) induced convulsion in mice. At both doses it significantly $(P<0.0001)$ increased latency of convulsions as well as reduced the duration of convulsion in dose dependent manner (Table 4). Protective effect of ELECC against PTZ induced mortality was found to be $66.66 \%$ and $83.33 \%$ protection for $100 \mathrm{mg} / \mathrm{kg}$ and $200 \mathrm{mg} / \mathrm{kg}$ of doses 
respectively which is comparable to standard drug Diazepam (Table 5).

In above model, the level of GABA amino acid neurotransmitter was significantly $(P<0.0001)$ elevated by ELECC in dose dependent manner when compared with control which is comparable to standard whereas, the level of Glutamate amino acid neurotransmitter was significantly $(P<0.0001)$ reduced by both the doses of ELECC that is $100 \mathrm{mg} / \mathrm{kg}$ and $200 \mathrm{mg} / \mathrm{kg}$ when compared with the control (Table 6).

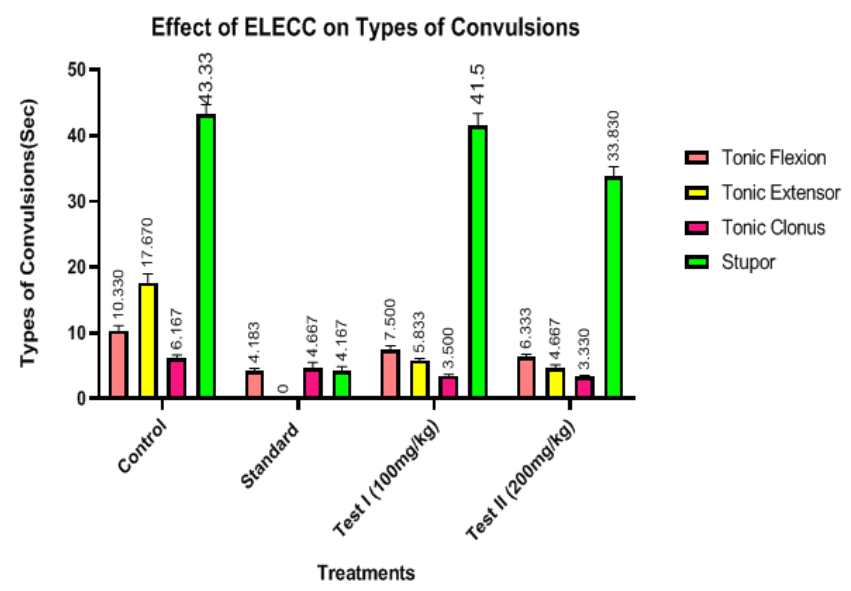

Fig. 1: Effect of ELECC on various phases of convulsions in MESinduced convulsions in rats

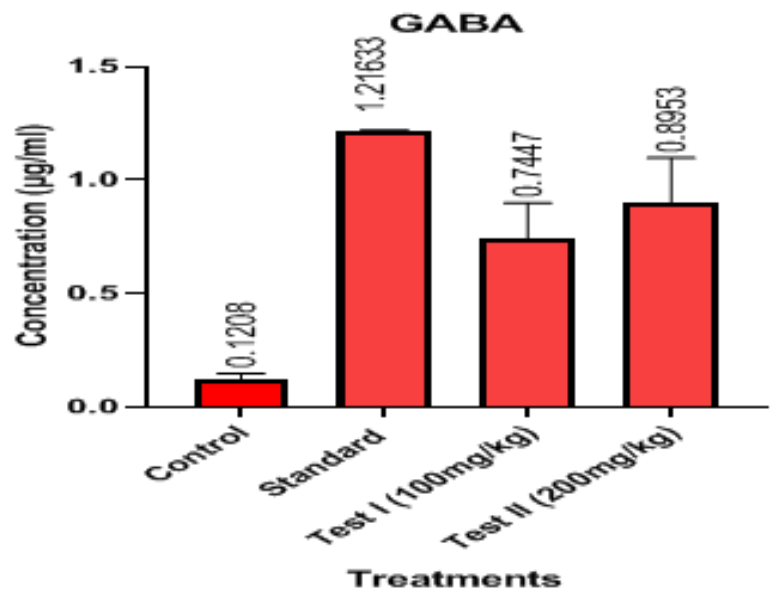

Fig. 2: Level of GABA amino acid neurotransmitter in MESinduced convulsions in rats

\section{Glutamate}

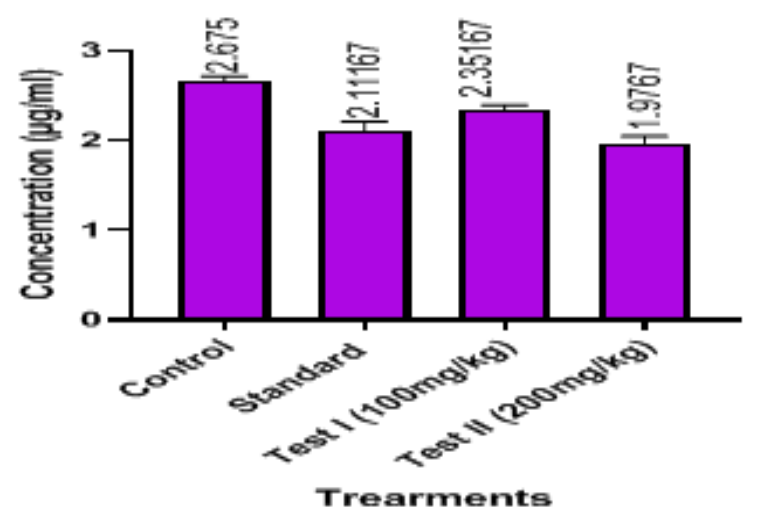

Fig. 3: Level of Glutamate amino acid neurotransmitter in MESinduced convulsions in rats
Onset of Latency

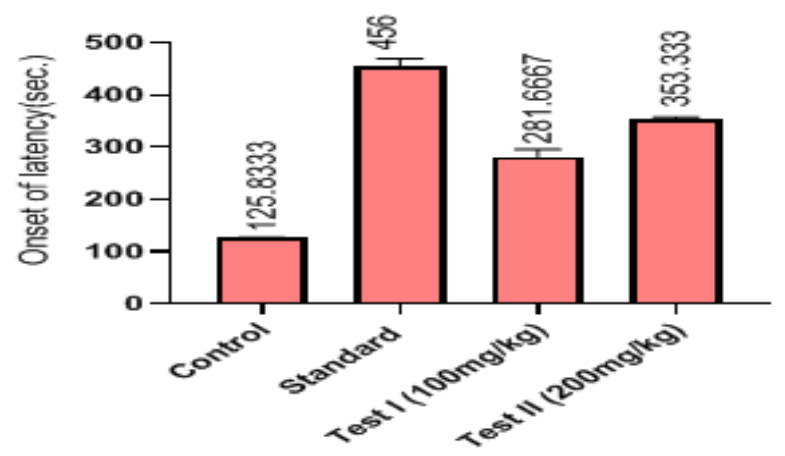

Fig. 4: Effect of ELECC in PTZ-induced convulsions in mice

Duration (Sec)

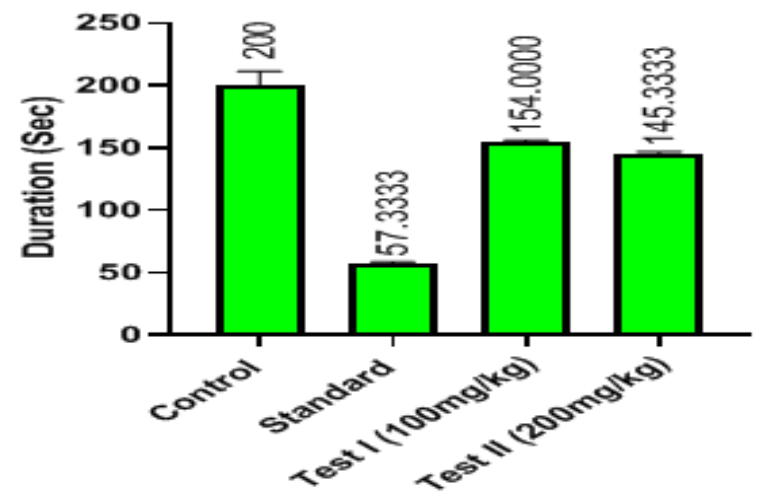

Fig. 5: Effect of ELECC in PTZ-nduced convulsions in mice

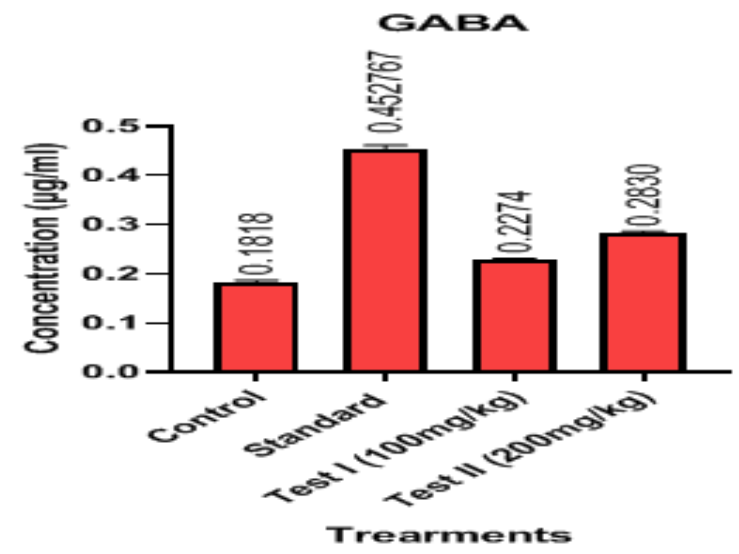

Fig. 6: Level of GABA amino acid neurotransmitter in PTZ-induced convulsions in mice

GLUTAMATE

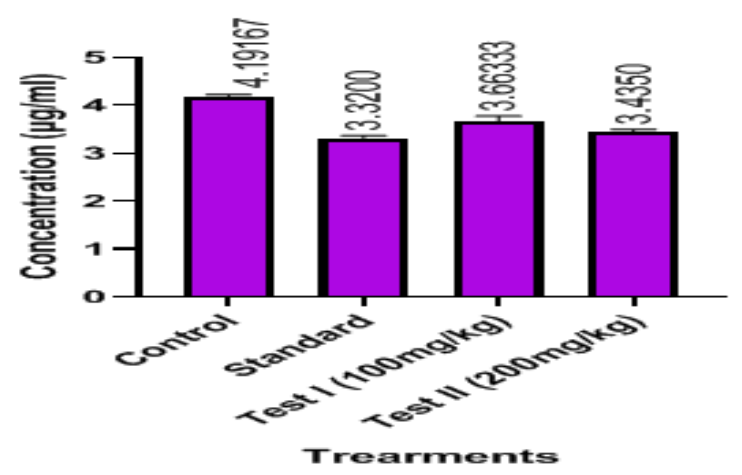

Fig. 7: Level of GABA amino acid neurotransmitter in PTZinduced convulsions in mice 


\section{DISCUSSION}

Neurological disorder like epilepsy is that impacts a broad variety of individuals worldwide. It is neurologist's second most prevalent chronic neurological disorder. India has approximately 10 million individuals with epilepsy (about 1 percent incidence). Medicinal plants are regarded readily accessible, economical and efficient sources of medication from the earliest moments known to man. People tend to depend for chronic circumstances on traditional and other types of corresponding and optional medicine that do not react well to standard or modern drug therapy. Neurological disorders like epilepsy, anxiety, and pain are among these. They are a powerful solution to modern medicine. Therefore, pharmacological assessment and standardization of such medicinal plant is the need for an hour.

C. Cajan has traditionally been asserted to be helpful in treating epilepsy therefore, taking into account the need for medicinal plants as an alternative to modern medicine and traditional claims about C. Cajan in epileptic therapy. [17] As research into epilepsy management and improvement in AED relies on the studies in rodents. Studies in experimental animals are used as to do research in epilepsy and growth of AED. MES and PTZ-induced convulsions are stronghold of an AED screening protocols.

In MES and PTZ-induced seizures in rodents were assessed for C. cajan by MES and PTZ induced seizures in rodents. The MES is likely the best technique for generalized evaluation of AEDs in generalized tonic clonic seizures. MES creates several cellular level modifications that interrupt the neuronal signal transduction. As an important and significant processes is to facilitate large-scale $\mathrm{Ca}^{2+}$ entries into the neuronal cell that extend the length of the seizure.

Apart from this, MES also facilitates the entry of other positively charged ions like $\mathrm{Na}^{+}$, blockade of which can prevent the AEDs like Phenytoin act by modifying the way of respected ions. There is also substantiation that respective plant possesses replaced flavanone. Pinostrobin inhibits voltage-gated sodium channels of human being's brain based on this substance's capacity to suppress depolarizing impacts of sodium channel selective veratridinein the rodent's brain synaptosomal preparation. [18]

It has been discovered that the ELECC has important anticonvulsant property by p.o. route in opposition to MES induced convulsions in rat. The duration of HLTE (Hind Limb Tonic Extensor) of $100 \mathrm{mg} / \mathrm{kg}$ along with $200 \mathrm{mg} / \mathrm{kg}$ dose of ELECC is $5.833 \pm 0.3073$ and $4.667 \pm$ 0.469 seconds respectively is very significant ${ }^{* * * *} P<$ 0.0001) as compared to control whereas, Phenytion showed total abolishment of HLTE phase. There are also seen the significant reduction in duration of tonic flexion as well as tonic clonus phases of convulsions. The protective effect of ELECC in MES-induced convulsions showed $66.66 \%$ and $83.33 \%$ of $100 \mathrm{mg} / \mathrm{kg}$ along with $200 \mathrm{mg} / \mathrm{kg}$ of doses respectively, which is comparable to standard.

The PTZ-induced seizures are associated with absence seizures. PTZ may be exhibiting its paroxysmal effect by diminishing the activity of GABA at $\mathrm{GABA}_{\mathrm{A}}$ receptor, implicated in epilepsy. The convulsive effect of PTZ may blocked by drugs like Diazepam which acts through GABAergic receptors. The ELECC improved the onset of latency of seizure that is $281 \pm 14.24$ and $353 \pm 4.944$ seconds of $100 \mathrm{mg} / \mathrm{kg}$ and $200 \mathrm{mg} / \mathrm{kg}$ of doses respectively where the increase in onset of latency by $200 \mathrm{mg} / \mathrm{kg}$ dose of ELECC is more significant and comparable to standard Diazepam. The protective effect of ELECC in PTZ induced seizures showed $66.66 \%$ and $83.33 \%$ of $100 \mathrm{mg} / \mathrm{kg}$ along with $200 \mathrm{mg} / \mathrm{kg}$ of doses respectively whereas, $100 \%$ protection was showed by Standard Diazepam.

According to pathophysiology of epilepsy, the imbalances between the exciting and inhibitory neurotransmitters are often liable for seizure activity formation when Glutamic acid exciting neurotransmitter is mediated by GABA inhibition over rides. [19-20] GABA is major inhibitory neurotransmitters of CNS dependent effects including anticonvulsant effect. In present study, the level of GABA was significantly $\left({ }^{* * *} P<0.0001\right)$ elevated by ELECC in MESinduced convulsion model as well as PTZ-induced convulsion model in dose dependent manner which is significantly comparable to respective standards.

Glutamate is the brain's foremost exciting neurotransmitter. In Epileptogenesis, it also plays a significant role. The hypothesis is attractive when glutamate transport is blocked and surplus glutamate accumulates in the synaptic room, resulting in enhanced NMDA activation of the receptor, further release of glutamate and seizure activation. And some childhood epilepsy may be partly linked to glutamate dysfunction of the transporter. A significant future step is to demonstrate that improving the function of glutamate transporters can safeguard animals from seizures. In present study the level of Glutamate was significantly $\left({ }^{* * *} P<0.0001\right)$ reduced by $200 \mathrm{mg} / \mathrm{kg}$ dose of ELECC in MES-induced model but it is significantly reduced $\left({ }^{* * *} P<0.0001\right)$ by both doses of ELECC in PTZinduced convulsion model in dose dependent manner which is comparable to standard.

From these results it is concluded that ELECC might have acted on glutamate transporters and inhibited the glutamate mediated excitatory effects by blocking NMDA receptors. Thus, investigation of ELECC showed significant anticonvulsive activity against MES and PTZ inducted seizures in rodents; the likely cause of the extract's anticonvulsant activity because of GABAergic neurotransmission potential or Glutamenergic neurotransmission inhibition. The phytochemical study of C. cajan Showed the occurrence of Glycosides, Flavonoids, Flavonones, Steroids, Tannins, Fixed oil, Fatty acids and Proteins. The herbal 
plants containing froth forming substance (saponins) or else flavonoids reveal anticonvulsant activity. Further, research is required to elucidate its specific mechanism of action and isolation of responsible active principles.

\section{REFERENCES}

1. Bodhankar SL, Vyavhare NS. A Textbook of Pathophysiology. Edn 4. Nirali Prakashan, Pune, 2007. pp. 3.1-3.18.

2. Shakirullah, NA, Khan A, Nabi M. The Prevalence, Incidence and Etiology of Epilepsy. International Journal of Clinical and Experimental Neurology. 2014; 2(2): 29-39.

3. Ramani SG, Bajracharya R. Antiepileptic and Anxiolytic Activity of Ethanolic Extract of Brassica nigra L. Koch Seeds on Wistar Albino Rats. European Journal of Pharmaceutical and Medical Research. 2016; 3(4): 394-402.

4. Herbal remedies used in the treatment of Epilepsy. [Internet] $2019 . \quad$ Available from <https://www.pharmatutor.org/articles/herbal remedies used in the treatment of epilepsy [Accessed on: 4 Aug 2018]

5. Mukhopadhyay HK, Kandhar CC, Das SK, Ghosh L, Gupta BK. Epilepsy and its Management: A Review. Journal of Pharmacology. 2012; 1(2): 20-26.

6. Patil CD, Ahire YS, Pathade DA, Pathade VV, Mali PR. Free radicals, epilepsy and antioxidant: An overview. International Research Journal of Pharmacy. 2011; 2(2): 64-71.

7. Asmatanzeem B, Parashivamurthy BM, Shaik KN. Evaluation of Anticonvulsant Activity of volatile oil extract of Nigella sativa seeds by chemically induced seizure model in albino rats. International Journal of Basics and Clinical Pharmacology. 2016; 18: 1300 - 1307.

8. Quintans JLJ, Almeida JRGS, Lima JT, Nunes XP, Siqueira JS, de Oliveira LEG, et al. Plants with anticonvulsant properties a review. Brazilian Journal of Pharmacognosy 2008; 18 (Supl.):798-819.

9. Pal D, Mishra P, Sachan N, Ghosh AK. Biological activities and medicinal properties of Cajanus cajan (L) Millsp. Journal of Advanced Pharmaceutical Technology and Research, 2011; 2(4): $207-213$.
10. Jaliwali YA, Mohanti PK, Jain NK. Antiulcer and Antiinflammatory Activity of Cajanus cajan Linn. International Research Journal of Pharmacy. 2014; 5(4): 313-316.

11. Khandelwal KR. Practical Pharmacognosy. 22nd ed. Pune: Nirali Prakashan; 2012. p. 25.1-25.9.

12. H. Gerhard Vogel (Ed). In: Chapter E, Vogel WH, Scholkens BA, Muller J, Vogel WF (eds.) Drug Discovery \& Evaluation. Pharmacological Assays. Ed. 2. New York: Sringer -Verlag; 2002. pp. 487-491

13. Kulkarni SK. Handbook of Experimental Pharmacology. Ed. 3. Vallabh Publication, Mumbai, 2011. pp. 131-134.

14. Kasturi S, Kavimani S, Devi R, Sundharajan R, Deepa N. Anticonvulsant activity of Mahakalyanaka Ghrita in Maximal Electroshock and Pentylenetetrazole induced seizures in rats. International Research Journal of Pharmacy. 2015; 6(10): 715719 .

15. Rahman Habibur, Eswaraiah MC. [Internet] Available from: https:// www.pharmatutor.org/articles/simple spectroscopic - method - estimating - brain neurotransmitter - antioxidant - enzymes - lab - animals (Accessed on: 7 August 2018)

16. Sancheti JS, Shaik MF, Khatwani PF, Kulkarni SR, Sathaye S. Development and Validation of HPTLC method for simultaneous estimation of L-Glutamic Acid in mice brain Indian Journal of Pharmaceutical Sciences. 2013; 75(6): 716721.

17. Joy Elizabeth A, Thalanjeri P, Manikkoth S. Anticonvulsant activity of Moringa oleifera in swiss albino mice. International Journal of Applied Biology and Pharmaceutical Technology. 2015; 6(2): 140-146.

18. Myanglambam DM, Leisangthem DT, Nameirak Pam DM, Krishna Khondram DP, Akham DS. Anticonvulsant effect of Portulaca oleracea in experimental animal models. Journal of Medical Society. 2016; 30: 94-97.

19. Shetty AK, Vinutha N, Kalleshappa CM, Akshata, Krupanidhi AM. Antiepileptic activities of ethanolic extract of leaves of Chromolaenaodarata. IOSR Journal of Engineering. 2017; 7(3): 66-69.

20. Sankari M, Chitra V, Silambu JP, Raju D. Anticonvulsant activity of ethanolic extract of Aegle marmelos (leaves) in mice. International Journal of PharmTech Research. 2010; 2(1): 640643.

HOW TO CITE THIS ARTICLE: Kore AP, Naikwade NS, Ladda PL, Shikalgar TS, Patil SS. Evaluation of Anticonvulsant Activity of Ethanolic Extract of Leaves of Cajanus cajan (L) Millsp. In Rodents. Int. J. Pharm. Sci. Drug Res. 2019; 11(6): 330-336. DOI: 10.25004/IJPSDR.2019.110608 